\title{
Socio-cyberphysical systems and intellectual space in the development of the Arctic zone of the Russian Federation ${ }^{a}$
}

\author{
Nikolay Didenko ${ }^{1 *}$, and Djamilia Skripnuk ${ }^{1}$ \\ ${ }^{1}$ Peter the Great St. Petersburg Polytechnic University, Institute of Industrial Management, \\ Economics and Trade, 195251 Polytechnicheskaya st. 29, Russian Federation
}

\begin{abstract}
The article states the new technical basis of production, which is socio-cyberphysical systems and intellectual space, and also analyzes the current state of studies on the problem regarding the development of sociocyberphysical systems and intellectual space. The concepts definition is described - socio-cyberphysical systems and intellectual space. The paper proposes to take the target subspaces of the Arctic territory of the Russian Federation as a territory for application of socio-cyberphysical systems and intellectual space. There are seven types of target subspaces for the Arctic development as the targets for the ideology of socio-cyberphysical systems and intellectual space: base cities, mobile filed camps, territories for mineral resources extraction, recreational areas, fishing grounds, northern sea route, safe existence protection infrastructure. The article outlines the concept of building socio-cyberphysical systems and intellectual space. The global conceptual goal of the Russian Arctic development is stated as a transition to the functioning of the Arctic zone in the mode of sustainable development on the basis of socio-cyberphysical systems and intellectual space. The targeted integrated programs have been conceptually selected as a tool for arrangement and management of the socio-cyberphysical systems and intellectual space development in the target sub-spaces of the Arctic zone of the Russian Federation.
\end{abstract}

\section{Introduction}

The term Cyber Physical System (CPS) appeared in 2006 and is a promising innovation line. The socio-cyberphysical systems are an information technology concept that implies the integration of various technical systems including Cyber Physical Systems into the integral part with person involvement in this system and able to adapt to environment changes.

The intellectual space is the cumulative result of human activity and idea complex. The cumulative result of human activity is associated with the territory, where people live and which is developed. The idea complex is associated with the probable transformation of the

\footnotetext{
${ }^{a}$ The paper is based on research carried out with the financial support of the grant of the Russian Science Foundation (Project No. 14-38-00009)

*Corresponding author: didenko.nikolay@mail.ru
} 
territory. The intellectual space can exist in the form of data banks, databases, knowledge bases, technologies for their maintenance and application, information telecommunications systems. The intellectual space is a data representation of the essential properties and states, as well as the relationship with the external world of the territory where people live and which is developed.

The problems discussed in this article are unique from the point of scientific research in the world science, as, firstly, the whole complex of problems in the socio-cyberphysical systems and intellectual space requires a continuous refinement of the properties and nature of the objects in question for their correct description. Secondly, as in any multi scale system, the very approach to solving emerging problems fundamentally excludes the classic approaches with centuries-old traditions of "physical" experiment. The approach to solving emerging problems assumes extensive application of mathematical modeling and the methods of "Computational Economics" as a new field of analysis of this research of the socio-cyberphysical systems and intellectual space. In the part of the "Computational Economics", which studies the economic processes of dynamic systems of interacting active rational agents, a widely recognized tool for studying such systems is computer agent-based modeling. The main researchers in this area shall be considered companies and developers of simulation platforms.

The current state of research on the problem of the socio-cyberphysical systems and intellectual space development is characterized by the fact that the approaches to individual sub-areas for the territory development on the basis of socio-cyberphysical systems and intellectual space are actively developing in a number of countries. The socio-cyberphysical systems are the types of systems that shall firstly be conceived and developed taking into account both technological and organizational aspects from the earliest stages. In fact, the design of such systems requires a suitable combination of beneficial technologies in the operational structure, integrating and coordinating the set of processes managed by complex organizations, each of which consists of independent and autonomous units. Along here the problems in the identification and development of adaptation systems for technical networks for smart spaces are discussed which are selected to focus, in particular, on (a) the social and technical model and process, (b) a multilevel integration structure, and (c) systems analysis methods for adaptation at runtime. Perspective robotic technology systems, socio-cyberphysical systems can not exist without artificial intelligence, which in turn depends on computational capability.

Significant scales in solving particular problems related to socio-cyberphysical systems and intellectual space are performed at the National Institute of Standards and Technology (NIST), where the higher priority is given as a whole to the problem of socio-cyberphysical and intellectual systems. The NIST philosophy presents the examples of cyber-physical systems: robots, smart buildings, medical implants, autonomous cars and drone aircraft. One of the most important challenges in the area of design, development and management of these cyber-physical systems is the issue of combined action of cyber-physical systems and people.

The issues that play an important role in the analysis and design of cyber-physical systems are the definition and modeling of the "situational understanding" (in other words, to be aware of what's going on around) of the human experience in interaction with these systems and the environment, as well as change in general circumstances and / or separate parameters created by these systems. The cyber physical systems in the NIST vision form the basis for the development of production, in particular, in the following areas: smart production, smart healthcare, smart grid infrastructure, smart buildings and infrastructure, smart cars, mobile systems and defense systems.

From the development of the software for intelligent systems, the world's leading research centers are the research universities specializing in engineering and technology: 
Eindhoven University of Technology (TU / e); the University of Science and Technology Beijing, China; Inria - Institute for Research in Computer Science and Automation, France; The National Center for Scientific Research (CNRS), France. Studies of sociocyberphysical systems (SCPS) in relation to production networks are actively performed in Brazil (Federal University of Santa Catarina, Brazil) and Germany (University of Bremen, Bremen, Germany).

The authors who study various aspects of socio-cyberphysical systems can be identified.

So Giacomo Cabri Massimo Cossentino et al study adaptive social and technical systems for intellectual spaces [1]. A group of Chinese scientists (Tao Zhang, Qing Li, Chang-shui Zhang et al) classify the technologies used for intelligent autonomous systems [2]. Intellectual unmanned autonomous systems are one of the most important applications of socio-cyberphysical systems. The development of such systems can significantly contribute to innovations in artificial intelligence technologies. The studies of Chinese scientists include the trends in the development of intelligent autonomous systems by summarizing the main achievements of each technological platform. The classification is applied to the appropriate technologies including artificial intelligence ones, unmanned vehicles, drone aircraft, service robots, space robots, marine robots and intelligent plants.

G. W. Gabrielsen [3], Enzo Morosini Frazzon, Jens Hartmann et al. are actively engaged in the design of adaptive social and technical systems for intellectual spaces. [4].

The socio-cyberphysical systems are studied from the point of various production, transport and trade operations, using the potential of the cyber physical system to determine human behavior using large data analytics [5]. In this case, contextual variables are identified that determine the cultural, administrative (or institutional), geographic and economic (including the infrastructure) environment, where these operations are planned. The importance of socio-cyberphysical systems in logistics [6], energy [7] is noted, as they significantly rely on the complex and dynamic interactions with the environment.

The study of socio-cyberphysical systems from the interaction between the physical and cyber world allows considering the socio-cyberphysical systems as the most effective and stabling systems in the process of their implementation [8]. In this case, a new challenges class arises, a new field of studies related to the modeling, design and testing of sociocyberphysical systems prior to their implementation is opened [9], [10]. The methods and tools associated with the physical and cyber space are not suitable for the sociocyberphysical systems.

\section{The target subspaces of the Arctic territory of the Russian Federation - the areas for application of socio-cyberphysical systems and intellectual space}

The general feature of this region being unique by geographical location, natural resources and military-strategic importance is: insufficient population of the territories, insufficient labor force for development, urbanization, severe climate and uncomfortable living conditions, the need to preserve the territory ecosystems, the presence of waste and pollution from human activity [11].

In terms of actual technological achievements and trends, the global conceptual goal of the Russian Arctic development can be stated as a transition to the functioning of the Arctic zone in the mode of sustainable development on the basis of socio-cyberphysical systems and intellectual space. Representation of the Arctic space of the Russian Federation as a set of target subspaces is a general conceptual idea of the organization and management of the development of the Arctic space of the Russian Federation. 
The subspace is a part of the Arctic space, which has a number of distinctive features (attributes) that allow for the functional division of the Arctic territory also characterized by a special development goal. The subspace as a part of space has physical boundaries, but the sub-spaces do not require to be set by boundaries of the administrative-territorial entities of the regions.

The objective for arrangement of the Arctic territories development currently facing the government requires the cooperation of various participants in the process to achieve a synergistic effect. The physical unification of regions and municipalities to ensure effective development of the Russian Arctic is undoubtedly impossible (or, at least, difficult) for administrative and legal reasons: this may require both a change in the territorial division of the country and the transformation of the regulatory bodies. At the same time, the Arctic subspaces as target management objects can be more flexibly integrated into a network of interactions.

The next argument in favor of applying the principle of dividing the Arctic space into target components is the relative homogeneity of different types of subspaces in comparison with municipalities that allows more adequate aggregation and modeling of the necessary processes. Indeed, the municipalities that form the Russian Arctic space differ in a number of indicators, and to arrange the reclamation and development of their territories, an individual account of all the features of these regions is required. At the same time, the target subspaces (within a separate type) are quite similar in their key characteristics (the main reason is that the target subspaces are not the complex entities as the Arctic regions). In other words, each separate region (not necessarily the Arctic one) can be represented as the target subspaces, but the subspaces need not be limited to the administrative-territorial division of regions.

Among the possible types of target subspaces that compose the Arctic zone of the Russian Federation, there are [12, 13]:

a) The base cities are large and medium populated and production points, which are presently not so much in the Arctic space of the Russian Federation. The base city means a territorial unit with a mixed building and a population of at least one thousand people in the territory of which there are industrial organizations, construction sites, railway terminals and other industrial infrastructure facilities, as well as commercial, domestic, medical, cultural, educational and administrative facilities. As examples of subspaces, of the "basic city" type, we can name such settlements as Murmansk, Apatity, Severomorsk, Monchegorsk, Kandalaksha, Naryan-Mar, Iskateley settlement, Anadyr, Bilibino, Pevek, Novy Urengoy, Noyabrsk, Salekhard, Nadym, Muravlenko, Labytnangi, Chokurdakh, Saskylakh, Tiksi, Chersky, Deputatsky, Vorkuta, Norilsk, Dudinka, Igarka, Arkhangelsk, Novodvinsk, Severodvinsk, Mezen, Kamenka, Onega, etc.

b) Mobile field camps are one of the ways to develop the Arctic territories, where arrangement of permanent household, cultural, educational and other types of infrastructure is difficult and economically unprofitable. Mobile field camps are usually located near deposits of mineral resources or within the areas of infrastructure facilities construction and maintenance.

The main criterion of this sub-space type is its "project" focus: the field camp is created to perform a specific objective (mining operations in harsh environment, construction, etc.), after which it can be moved, demolished or converted in a complete basic city.

c) Territories of mineral resources extraction. These areas mean deposits and industrial facilities constructed for extraction of minerals. Let us emphasize once again that the concept of "the territory of mineral resources extraction" is not limited only to the definition of the resource field (i.e., minerals accumulation); the explored or suspected deposits, where direct extraction of resources has not yet begun, do not belong to the category of this target sub-space [13]. 
d) Recreational areas. These areas include such objects of tourist interest as reserves, national parks, zones of eco-, ethno- and extreme tourism and other attractions of the Arctic space that form a network of Arctic tourism. A. Kajan [14], J. Dawson, M.E. Johnston, E.J. Stewart [15], N. Didenko, D. Skripnuk, and O. Krasulina [12] present the prospects for the development of polar tourism and its impact on the welfare of the indigenous population. As examples of recreational areas, it is possible to identify the natural-ethnic park "Beringia" in the Chukotka Autonomous District, the geological natural monument of regional importance "Kharberiysky" in the Yamal-Nenets Autonomous District and the Lapland Reserve in the Murmansk Region.

e) Fishing grounds. Similarly, as in the case of mining areas, this concept does not exclusively include the variety of fish resources available for catching; this target sub-space includes the means and infrastructure for commercial fishing. Arctic fishing is a special economy branch the development of which requires an extremely circumspective approach because of the fragility of the Arctic ecosystem and its susceptibility to climate change [16]. As examples of fishing grounds, it is possible to distinguish water areas of the Murmansk Region (included in the Barents-Belomorsk Territorial Administration of the Federal Agency for Fishery) and the Yamal-Nenets Autonomous District (included in the Nizhneobsk Territorial Administration of the Federal Agency for Fishery).

f) Northern Sea Route. According to the legislation of the Russian Federation, the water area adjacent to the Northern Sea Route of the Russian Federation covering the internal sea waters, territorial sea, the adjacent zone and the exclusive economic zone of the Russian Federation and bounded at the east by the line of separation of sea areas with the United States of America and parallel to Cape Dezhnev in the Bering Strait, at the west by the meridian of Cape Zhelaniya to the Novaya Zemlya Archipelago, the eastern coastline Novaya Zemlya Archipelago and western boundaries of straits Matochkin Shar, Kara Strait, Yugorski Shar [17 - 19].

This target subspace differs from all the other ones listed above both by its size (extension), and its complexity, as well as by the variety of connections with other subspaces. The Northern Sea Route is allocated as a separate target sub-space, primarily because of its geo-economic importance (other transport corridors of the Arctic zone, which are a part of the infrastructure providing the interaction of sub-spaces in network formations have no similar strategic importance for the development of the country's economy) [18, 19].

The Northern Sea Route comprises not only a possible shipping route, but also port and service institutions that make up its sub-space [20].

g) The infrastructure for protection of safe existence is a target sub-space that performs the functions for protection of safe existence and development of the Arctic space. The Arctic security system shall consist of various defense establishments and facilities, threat detection and prevention services, means for security of communications and information, customs, ecology, reconnaissance satellites, etc. Military settlements, bases, educational formations shall also be assigned to this type of subspaces [21 - 23].

Thus, the Arctic space division into the sub-spaces is of a functional nature: each type of sub-space performs various functions in accordance with its inherent attributes - integral and necessary properties.

\section{The concept of building socio-cyberphysical systems and intellectual space}

The concept includes a methodology for classification of processes that are developed based on the principles of key technological trends underlying the socio-cyberphysical systems in the framework of the concept of development of the Arctic zone of the Russian 


\section{Federation.}

The concept includes the main manifestations of technological mega-trends that are crucial in the innovative and technological development of the Arctic zone of the Russian Federation and are based on the possibility for creation of the socio-cyberphysical systems: power supply technologies for the Arctic territories based on mobile nuclear power plants and renewable sources; subsea hydrocarbon production on the shelf; use of unmanned vehicles; additive technologies and 3D printing; advanced robotics; new materials; the Internet of Things; radio relay - tropospheric communication; use of space technologies in the development of the Arctic (a system of satellites in the Highly Elliptical Orbit); automated complexes that can be used for underwater (ice) operations on the Arctic shelf for monitoring the environmental situation, minerals exploration; digital technologies in economic activity; natural gas aircraft; telemedicine and mobile health systems in the Arctic; sanitary drone aircraft; systems of distance production training at enterprises operating within the regions of the Arctic.

The concept includes the structure of the intellectual space of the Arctic zone of the Russian Federation: (a) conceptual models of the Arctic zone of the Russian Federation presenting the activity of agents in the Arctic zone of the Russian Federation by mathematical and logical tools; (b) a set of databases being the initial information for building a set of conceptual models of the Arctic zone of the Russian Federation; (c) a combination of ideas, tools, models and devices for analyzing and comparing the conceptual models of the Arctic zone of the Russian Federation; (d) a set of technological driver bases and technological mega-trends, developing technological revolution for the use in the innovation and technological development of the Arctic zone of the Russian Federation.

The use of socio-cyberphysical systems and intellectual space for the development of target subspaces of the Arctic zone of the Russian Federation is based on the following provisions:

(1) Development of the content and structure of the intellectual space of the Arctic zone of the Russian Federation.

(2) Development of the method for studying the intellectual space of the Arctic zone of the Russian Federation.

(3) The choice of a conceptual model for development of the Arctic zone of the Russian Federation, i.e. a set of key provisions that determine the lines, architectonics and various approaches to performance of economic activity in the Arctic zone of the Russian Federation.

(4) Development of the processes concept for each type of target sub-spaces based on the principles of key process trends that underlay the socio-cyberphysical systems for the Arctic zone of the Russian Federation.

(5) The analysis of collections of process driver bases and technological mega-trends, developing fourth industrial revolution, for use in innovation and technological development of each type of target sub-spaces.

(6) Formation of the socio-cyberphysical systems "database" for application in the innovation and technological development of each type of target subspaces and analytical methods for on-line data assessment.

(7) Orientations to real objects - the target sub-spaces of the Arctic development in the extension and use of the socio-cyberphysical systems and the intellectual space of the Arctic zone of the Russian Federation, which are replaced with their simpler, safer and more accessible models which properties are similar to ones of the real objects under study in a certain substantial part.

The concept contains the methodological tools for forecasting the social and economic boundaries and assessing the risks of using the processes developing based on the principles 
of the socio-cyberphysical systems and the intellectual space for the development of the target sub-spaces of the Arctic of the Russian Federation, and assessment of risks to life under global changes taking place in the Arctic.

The targeted integrated programs have been conceptually selected as a tool for arrangement and management of the social and cyber physical systems and intellectual space development in the target sub-spaces of the Arctic zone of the Russian Federation. The target program is a set of research, production, design and experimental, socioeconomic, business management and other activities aimed at achieving the set goals, and coordinated by contractors, terms, resources and objectives.

The concept provides for the analysis of the problem, as well as the compilation of a possible forecast of situation development. At the preliminary stage of creating the target program, there are the following operations: problem identification, current situation assessment, forecast of its further development, and decision on the application of the program-target method. At the stage of creating the target program, its objectives are identified and structured. Such method as building the goals tree - the decision tree is used. The general goal is chosen and hierarchically divided into subgoals. The decision tree reflects the trends of long-term prospective study to a greater extent it shall be used to establish the hypothesis of the development of scientific trends, rather than to display target programs.

In the Concept, the study of socio-cyberphysical systems and intellectual space for the target sub-spaces of the Arctic zone is represented by an alternative structure graph under certainty, risk and uncertainty.

\section{References}

1. C. Giacomo, C. Massimo, D. Enrico, IEEE 25TH International Conference on enabling technologies: infrastructure for collaborative enterprises (WETICE) (2016)

2. T. Zhang, Q. Li, C.-S. Zhang, Frontiers of information technology \& electronic engineering, 18 (1) (2017)

3. G.W. Gabrielsen, Journal of Toxicology and Environmental Health, 77 (9-11) (2014)

4. E. M. Frazzon, J. Hartmann, T. Makuschewitz, B. Scholz-Reiter, Procedia CIRP, 7 (2013)

5. A. Awais, B. Muhammad, D. Sadia, K. Shehzad, M.-A. Nasro, Future Generation Computer Systems (2018)

6. E. M. Frazzon, S. Loureiro, Jr. O.F. Lima,B. Scholz-Reiter, Proceedings of 44th CIRP Conference on Manufacturing Systems (2011)

7. S. Poudel, Z. Ni, N. Malla, International Journal of Electrical Power \& Energy Systems, 90 (2017)

8. R. A. Rojas, E. Rauch, R. Vidoni, D. T. Matt, Procedia Manufacturing, 11 (2017)

9. J. Miranda, R. P.-Rodríguez, V. Borja, P.K. Wright, A. Molina, IFAC-PapersOnLine, 50 (1) (2017)

10. H. Zhuge, Artificial Intelligence, 175 (5-6) (2011)

11. D. Rudenko, N. Didenko, WELLSO 2015 - II International Scientific Symposium on Lifelong Wellbeing in the World, European Proceedings of Social and Behavioral Sciences, 7 (2015)

12. N. Didenko, D. Skripnuk, O. Krasulina, International Multidisciplinary Scientific Conference on Social Sciences and Arts, SGEM2016, V (2016) 
13. N. Didenko, D. Rudenko, D. Skripnuk, International Multidisciplinary Scientific GeoConference Surveying Geology and Mining Ecology Management, SGEM2015, III (2015)

14. A. Kajan, Scandinavian Journal of Hospitality and Tourism, 14 (1) (2014)

15. J. Dawson, M.E. Johnston, E.J. Stewart, Ocean \& Coastal Management, 89 (2014)

16. M. M. McBride, P. Dalpadado, K.F. Drinkwater, ICES Journal of Marine Science, 71 (7) (2014)

17. M. Blunden, International Affairs, 88 (1) (2012)

18. D. R. Rothwell, Ocean Development and International Law, 43 (3) (2012)

19. L. C. Smith, S. R. Stephenson, Proceedings of the National Academy of Sciences of the United States of America, 110 (3) (2013)

20. G. B. Stenson, M. O. Hammill, ICES Journal of Marine Science, 71 (7) (2014)

21. N. Hong, Journal of World Energy Law \& Business, 5 (1) (2012)

22. G. Backus, Bulletin of the Atomic Scientists, 68 (4) (2012)

23. N. H. Nicol, L. Heininen, Polar Record, 50 (1) (2014) 